\title{
Use of Gas Desorption Effect in Injection Systems of Diesel Engines
}

\author{
Maciej Bajerlein, Wojciech Karpiuk*(D) and Rafał Smolec (D) \\ Institute of Combustion Engines and Powertrains, Poznan University of Technology, 60-965 Poznan, Poland; \\ maciej.bajerlein@put.poznan.pl (M.B.); rafal.smolec@put.poznan.pl (R.S.) \\ * Correspondence: wojciech.karpiuk@put.poznan.pl
}

\section{check for}

updates

Citation: Bajerlein, M.; Karpiuk, W.; Smolec, R. Use of Gas Desorption Effect in Injection Systems of Diesel Engines. Energies 2021, 14, 244. https://doi.org/10.3390/en14010244

Received: 30 November 2020 Accepted: 30 December 2020 Published: 5 January 2021

Publisher's Note: MDPI stays neutral with regard to jurisdictional clai$\mathrm{ms}$ in published maps and institutional affiliations.

Copyright: (C) 2021 by the authors. Licensee MDPI, Basel, Switzerland. This article is an open access article distributed under the terms and conditions of the Creative Commons Attribution (CC BY) license (https:// creativecommons.org/licenses/by/ $4.0 /)$.

\begin{abstract}
The article presents a concept of improving operation of the engine with the effect of gas desorption from a solution with nucleation of gas bubbles. This concept consists in dissolving gas in diesel fuel until the solution is in equilibrium. At a later stage, the phenomenon is reversed, and the gas is released from the solution during its injection into the combustion chamber. The purpose of the study is to present the idea of the desorption effect along with a thermodynamic analysis of the process and to study its impact on the operation of a diesel engine. The article also describes the most important features of the injection pump adapted to employ the desorption effect, which is a proprietary, patented solution. The conducted engine preliminary tests concerned the most important parameters of the engine's operation (indicated pressure course, pressure growth rate, heat release rate, etc.) and the emission of harmful compounds (PM-particulate matter, $\mathrm{CO}, \mathrm{HC}$, and $\mathrm{NO}_{x}$-nitrogen oxides). A significant reduction of $\mathrm{PM}, \mathrm{CO}$, and $\mathrm{HC}$, with a simultaneous increase in $\mathrm{NO}_{\mathrm{x}}$ emissions obtained in tests, confirmed that the desorption effect facilitated engine operation.
\end{abstract}

Keywords: injection systems; gas dissolution; exhaust gas; desorption effect; injection pump; high-pressure pump; pump with hypocycloid drive; compression ignition engines

\section{Introduction}

Modern diesel engines, apart from their unquestioned advantages, also have certain disadvantages. The disadvantages include, first of all, excessive emission of solid particles, nitrogen oxides, hydrocarbons, and sometimes also carbon monoxide [1-8]. The main cause of these problems is the nature of the combustion process, which begins with the introduction of fuel into the combustion chamber. To achieve the correct atomization structure, the injection system design must generate very high pressure (above $180 \mathrm{MPa}$ ). Only at such high pressures can the requirements for both fuel consumption and exhaust gas emission be reconciled satisfactorily [9-11].

In conclusion of the above-mentioned remarks, it is necessary to answer a question as to whether the ongoing quest [12-17] to obtain increasingly higher pressures while trying to overcome the discussed problems is the only direction of development of injection systems. Is it possible to obtain the quality of fuel preparation, satisfactory in view of the combustion process, by other means, e.g., by increasing the number of stimuli sparking the stream decay mechanism?

The search for answers to these questions prompted researchers to propose a new concept for assisting the injection mechanism, which was named as the effect of gas desorption from a solution with nucleation of gas bubbles (in short "desorption effect"). The work is a continuation and extension of Kozak's research. In his works [18-22], he proved the existence of a positive impact of the desorption effect on the operation of engines.

One of the basic problems in the conducted experiments was related to the injection pump. Desorption is not possible in high-pressure pumps that use camshafts. This is due to the fact that if gas and fuel are fed to the pump discharge section during the suction stroke 
and the process of dissolution in the fuel is carried out during compression, the high-pressure pump would need to have radically different proportions compared to the existing pumps. Another problem was the size of the pump-compact dimensions had to be ensured.

Therefore, this article presents the general principle of ideas and undertakes two aspects related to this concept. The first of them focuses on the description of energy changes in the process of compressing gas in fuel using the effect. The second aspect concerns the results of an engine study in which the desorption effect was used. The results of the research are preceded by a description of research methods including the pump design and its operation enhanced with hypocycloidal drive. The pump is designed to allow the gas to dissolve in the fuel.

\section{The Nature of the Gas Desorption Effect from the Solution with Nucleation of Gas}

The concept of spray improvement is based on introducing the right amount of gas into the fuel, which is then dissolved in it; at the assumed injection pressure, the equilibrium is obtained. In the next step, the effect that accompanies the release of dissolved gas during injection into the combustion chamber (desorption effect) is exploited when a strong disturbance of the equilibrium occurs. This is due to the features of this solution-when the pressure is lowered, the excess of gas dissolved in the liquid spontaneously releases simultaneously from the entire volume. The decrease in pressure is accompanied by the decrease in the equilibrium thermodynamic potential. Thus, a negative pressure gradient is a thermodynamic stimulus that causes the release of gas from the solution. The rate of gas release is related to the rate of change of stimulus. The goal of the proposed concept is to obtain a better fuel injection, at least qualitatively, in comparison to that obtained with high pressure systems, while maintaining relatively low injection pressure values.

It is well known that gases dissolve poorly in liquids and that the amount of dissolved gas strongly depends on the pressure and temperature at which dissolution occurs [23]. Gas atoms (or molecules) in the solution state are dispersed uniformly throughout the liquid volume. By releasing simultaneously in the entire volume, the molecules form dispersed microbubbles, expand, and tend to merge. As a result, the volume is divided into two parts: one-occupied by the solution, the other one-occupied by gas. However, if the pressure drop occurs dynamically, then the microbubbles will not manage to combine into a single volume. The factor favoring the intensification of the gas desorption effect from the solution is therefore the speed of this process. This is beneficial for the engine. There is a significant pressure difference between the sac-hole from which the fuel flows out and the combustion chamber, through which the fuel goes. The fuel flows out at a short distance (length of the atomizer channels) and in a very short time. The simultaneous combination of these factors means a very high rate of pressure change during injection, and therefore a very large thermodynamic potential gradient. Therefore, if a fuel solution with gas is led to the atomizer pit, there are grounds to assume that during the outflow of fuel through the atomizer holes, the gas dissolved in the fuel, due to a rapid decrease in thermodynamic potential in the discharge path, should also begin to rapidly release from the solution. Thus, the described mechanism should cause the fuel droplets to be torn apart from the inside. Therefore, it will be an additional factor supporting the existing spraying mechanism.

According to the presented concept, in the high-pressure part of the injection system (from the high pressure pump up to the atomizer holes), the pressure should be maintained at such a level that the gas cannot escape from the solution. In this part of the system, the fuel with gas should be a homogeneous solution. Release of gas, combined with expansion, should only take place outside the atomizer to help break up the droplets along the fuel outlet. This process is illustrated qualitatively in Figure 1. 


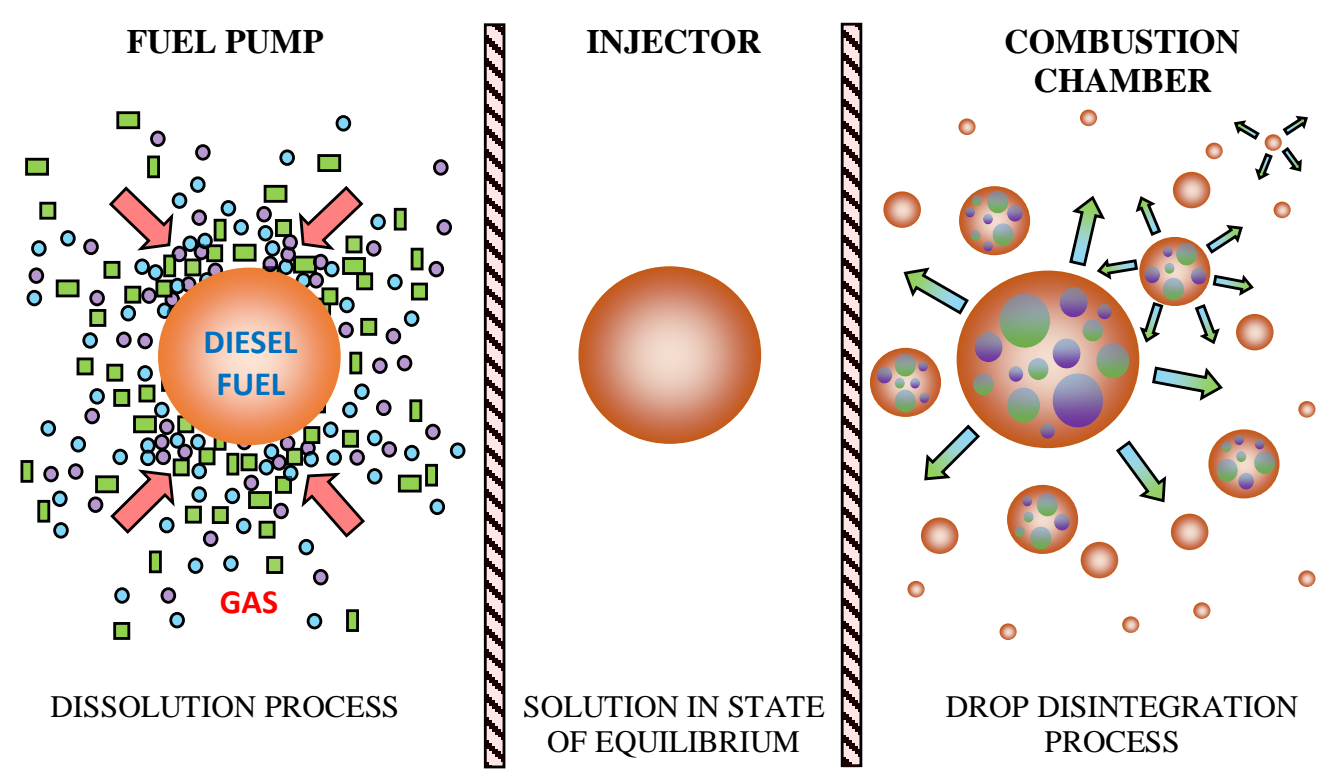

Figure 1. Illustration of the concept of spray support by gas dissolved in fuel.

The question arose as to which gas is most appropriate to be used in the process? The main assumption is that this gas must mix well with diesel fuel and that it has to be easily available in the engine environment. Considering this practical application, only two gases can be used to support the process of atomizing fuel:

- air that would be taken in directly from the engine environment;

- exhaust gas that would be taken directly from the exhaust manifold.

In [24], there is only datum on the value of solubility coefficients of chemically pure compounds. Unfortunately, both the fuel as a solvent, and air or exhaust gas, which are dissolved gas, are aggregation of chemical compounds. On the basis of existing data [23], it can be stated that $\mathrm{CO}_{2}$ dissolves in liquids several dozen times better than, for example, air.

The considerations provided thus far were of a qualitative nature. To better understand the nature of the process, it seems necessary to carry out its thermodynamic analysis. In particular, it is necessary to make an energy quantitative assessment-the question should be asked as to how significant energy changes will be caused by the introduction of gas into the fuel. This topic is discussed in the next chapter.

\section{Energy Changes in the Compression Process}

The compression caused by desorption changes the thermodynamic potential of the compressed medium. The question arose as to how much the thermodynamic potential of compression change is necessary if the fuel solution is compressed with gas instead of pure fuel. To answer this question, it is necessary to specify the change in specific enthalpy. On the basis of the first law of thermodynamics, it can be assumed that volume $\mathrm{V}$

$$
\mathrm{dH}=\mathrm{Vdp}+\mathrm{Q}_{\mathrm{el}}+\mathrm{W}_{\mathrm{el}}
$$

where $\mathrm{dH}$ is the change in enthalpy due to pressure change $\mathrm{dp}, \mathrm{Q}_{\mathrm{el}}$ and $\mathrm{W}_{\mathrm{el}}$ are heat and non-volumetric work (any work not related to volume change, e.g., friction work, etc.), respectively, brought to the analyzed volume $\mathrm{V}$ during compression.

It should be assumed that the compression process is adiabatic, and no volumetric work was carried out on the system, i.e.,

$$
\mathrm{Q}_{\mathrm{el}}=\mathrm{W}_{\mathrm{el}}=0,
$$


Then, when the pressure changes from $p_{1}$ to $p_{2}$, the enthalpy change can be calculated as

$$
\Delta \mathrm{H}=\mathrm{H}_{2}-\mathrm{H}_{1}=\int_{\mathrm{p}_{1}}^{\mathrm{p}_{2}} \mathrm{Vdp},
$$

For liquids, there is only one phase in the volume $\mathrm{V}$ during the entire compression process. However, for liquid and gas at the beginning of compression, at pressure $\mathrm{p}_{1}$, there must be two phases in volume V: liquid and gas. As the pressure increases due to the change in volume $\mathrm{V}$, apart from compressing the liquid and gas phases, the process of dissolving gas in liquid occurs simultaneously. Thus, the mass decreases and the volume of the gas phase decreases, and the mass and composition of the liquid phase changes. A solution of varying concentration is formed. When the gas is completely dissolved in the fuel, the gas phase disappears and only a solution of constant concentration is compressed.

Since the mathematical form of the equation of state for the liquid phase and the gas phase is different, the integration of Equation (3) should be divided into two parts. In the first part, the change in total enthalpy of volume $V$ is expressed by the sum of changes in the liquid phase enthalpy and the gas phase enthalpy. The upper integration limit is equal to the pressure $\mathrm{p}_{\mathrm{z}^{\prime}}$ at which the gas phase disappears. In the second part, there is only the liquid phase (solution) and the integration limits cover the range from $p_{z}$ pressure to $p_{w}$ injection pressure.

\subsection{Equation of State for the Liquid Phase}

In order to obtain the equation of the state of the liquid phase, it is necessary to begin with the definition of the coefficient of compressibility $x$ [25]:

$$
x=-\left(\frac{1}{\mathrm{~V}_{\mathrm{m}}}\right) \cdot\left(\frac{\partial \mathrm{V}_{\mathrm{m}}}{\partial \mathrm{p}}\right)_{\mathrm{T}}{ }^{\prime}
$$

where $V_{m}$ is the molar volume of diesel fuel. In practice, especially when considering liquids instead of the compressibility factor, its inverse, the compressibility module, is more often used. By introducing the modulus of compressibility B and assuming that the searched compound $\mathrm{V}(\mathrm{p})$ depends only on pressure, Equation (4) can be expressed as

$$
\frac{d V}{V}=-\frac{d p}{B},
$$

In hydraulic systems operating at relatively low pressures, it is generally assumed that $\mathrm{B}=$ const. It is different in the case of injection equipment, where due to high pressure, such a simplification cannot be made. In general, the modulus of compressibility is a function of pressure and temperature. Since the operating temperature of the injection system changes to a small extent, it is often assumed that the pressing process takes place in the isothermal conditions and the function $B(p)$ is in the following form:

$$
\mathrm{B}(\mathrm{p})=\mathrm{a} \cdot \mathrm{p}+\mathrm{b},
$$

where $\mathrm{a}$ and $\mathrm{b}$ are empirically determined coefficients.

In the case of a diesel fuel solution with gas, the function $\mathrm{B}(\mathrm{p})$ loses its linear nature. To estimate the changes in the thermodynamic potential of fuel with air and to describe relations B (p), the characteristics shown in Figure 2 in [26] were used. 


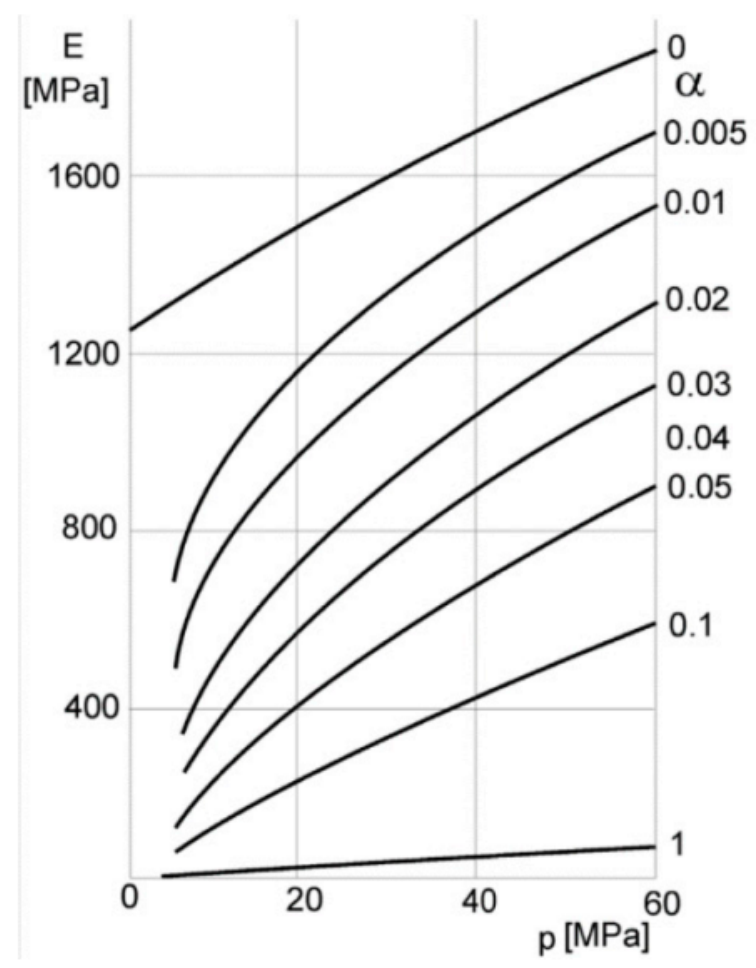

Figure 2. Dependence of the modulus of elasticity E of the air-fuel oil mixture on the pressure $\mathrm{p}$ and relative volume of air $\alpha$ [26].

The curves for changes in the diesel fuel compressibility module with air in the function of pressure can be described by a polynomial of the form:

$$
\mathrm{B}(\mathrm{p})=\mathrm{a} \cdot \mathrm{p}^{2}+\mathrm{b} \cdot \mathrm{p}+\mathrm{c},
$$

where the values of $a, b$, and c coefficients depend on the amount of air dissolved in the fuel. In this case, the amount of air contained in the fuel was determined by the air volume coefficient, defined as

$$
\alpha=\frac{\mathrm{V}_{\text {air }}}{\mathrm{V}_{\text {fuel }}+\mathrm{V}_{\text {air }}},
$$

For example, for $\mathrm{a}=0.005$ polynomial coefficients take the form

$$
\mathrm{a}=-0.1286 ; \mathrm{b}=24.971 ; \mathrm{c}=666 .
$$

Taking into account the above values, Equation (5) for the case of fuel without gas and the case of fuel with air will take the form

$$
\frac{d V}{V}=-\frac{d p}{a \cdot p+b} \text { and } \frac{d V}{V}=-\frac{d p}{a \cdot p^{2}+b \cdot p+c},
$$

Using substitution

$$
\mathrm{z}=\mathrm{a} \cdot \mathrm{p}+\mathrm{b}
$$

Equation (9) for the case of fuel without air can be simplified in the following way:

$$
\frac{\mathrm{dV}}{\mathrm{V}}=-\frac{1}{\mathrm{a}} \cdot \frac{\mathrm{dz}}{\mathrm{z}},
$$

in this case, the integral can be calculated. The integration limits should include the range of pressure changes in which the injection system works. Thus, at the lower limit, the pressure is close to the ambient pressure $\mathrm{p}_{\mathrm{o}^{\prime}}$ and the volume $\mathrm{V}_{\mathrm{o}}$ results from the diameter 
and stroke of the high-pressure pump piston. In the upper limit of integration, the pressure reaches the value of $\mathrm{p}_{\mathrm{w}}$, while the volume reaches the value of $\mathrm{V}$. Taking into account the above figures, the solution of Equation (9) can be represented in the form

$$
\ln \mathrm{V}=-\frac{1}{\mathrm{a}} \cdot \ln \mathrm{z}+\ln \mathrm{C},
$$

where $C$ is the integration constant; to facilitate calculations, it has been included in the form of $\ln$. Using the logarithm properties it can be written as

$$
\ln \mathrm{V}=\ln \left(\mathrm{z}^{-\frac{1}{\mathrm{a}}} \cdot \mathrm{C}\right),
$$

which allows logarithm to be removed. Returning to the original variable (10), an expression

$$
\mathrm{V}=\mathrm{C} \cdot(\mathrm{a} \cdot \mathrm{p}+\mathrm{b})^{-\frac{1}{\mathrm{a}}},
$$

is obtained.

The value of the integration constant $C$ can be calculated by applying the initial condition. At $\mathrm{p}=\mathrm{p}_{\mathrm{o}}$ the volume occupied by the fuel is $\mathrm{V}_{\mathrm{fo}}$. Thus,

$$
\mathrm{C}=\frac{\mathrm{V}_{\mathrm{fo}}}{\left(\mathrm{a} \cdot \mathrm{p}_{\mathrm{o}}+\mathrm{b}\right)^{-\frac{1}{\mathrm{a}}}}
$$

and the equation of state for the liquid phase of a fuel without gas will take the form

$$
\mathrm{V}=\frac{\mathrm{V}_{\mathrm{fo}}}{\left(\mathrm{a} \cdot \mathrm{p}_{\mathrm{o}}+\mathrm{b}\right)^{-\frac{1}{a}}} \cdot(\mathrm{a} \cdot \mathrm{p}+\mathrm{b})^{-\frac{1}{\mathrm{a}}},
$$

In the case of a fuel/gas solution, the integration result of Equation (9) depends on the sign of the difference:

$$
\mathrm{b}^{2}-\mathrm{ac},
$$

For the quoted coefficient values, this difference is positive, and the integration result is

$$
\ln V=-\frac{1}{2 \sqrt{b^{2}-a \cdot c}} \cdot \ln \left|\frac{a \cdot x+b+\sqrt{b^{2}-a \cdot c}}{a \cdot x+b-\sqrt{b^{2}-a \cdot c}}\right|+\ln C,
$$

Proceeding in the same way as for the case of fuel without gas, the logarithms must be removed from both sides of the equation. The integration constant $C$ can be calculated for the moment of disappearance of the gas phase (the gas phase has completely gone into solution), the pressure is $\mathrm{p}=\mathrm{p}_{\mathrm{z}}$; due to the low compressibility of the liquid phase, it can be assumed that the volume occupied by the solution is equal to the volume of fuel without gas $V_{\text {fo }}$. Taking into account the above and performing elementary transformations, we can obtain an equation as follows

$$
V=\frac{V_{f o}}{\left|\frac{a \cdot p_{z}+b+\sqrt{b^{2}-a \cdot c}}{a \cdot p_{z}+b-\sqrt{b^{2}-a \cdot c}}\right|^{-\frac{1}{2 \sqrt{b^{2}-a \cdot c}}}} \cdot\left|\frac{a \cdot p+b+\sqrt{b^{2}-a \cdot c}}{a \cdot p+b-\sqrt{b^{2}-a \cdot c}}\right|^{-\frac{1}{2 \sqrt{b^{2}-a \cdot c}}},
$$

Equation (14) is the equation of the state of the fuel/gas solution that can be used to calculate the change in enthalpy of the solution during compression, expressed by Equation (2).

For the fuel-free gas case, the entire volume $V_{o}$ is filled with a homogeneous liquid. Therefore, only the fuel is subjected to compression and for the enthalpy calculation it is enough to substitute the relation (12) into Equation (2), and then calculate the integral in the range from the ambient pressure to the pressure $\mathrm{p}_{\mathrm{w}}$ occurring during injection. 
The gas/fuel case is much more complex. If we assume that the process of gas dissolution in the fuel will take place in the pump, volume $V_{o}$ is filled with fuel only partially. Undissolved gas will occupy much larger part of this volume. During compression, the gas will change into a solution and hence its volume will decrease to zero, providing a complete dissolution. From this moment, only the fuel solution with gas will be compressed. Thus, in the initial stage of the pressing process, the two-phase medium is compressed. The liquid phase changes its composition (gas concentration increases), and the volume of the gas phase decreases. In the second phase, after the gas is completely dissolved, a homogeneous solution is compressed. These issues should be taken into account when calculating the enthalpy change during compression. Until the complete dissolution of the gas, the enthalpy increase in the analyzed volume should be calculated as the sum of the increase of both the liquid and gas phase enthalpy. After dissolution, only the liquid phase exists in the volume. Enthalpy of the liquid phase can be calculated on the basis of Equation (14), while for the gas phase, on the basis of the commonly known state equation for gases.

\subsection{Equation of State for the Gas Phase}

The process of gas compression takes place in the environment of a liquid, a medium with high specific heat and latent heat of evaporation. In the real construction, heat will also be released to the pump walls. To estimate the differences in the energy effect, we assumed that the compression process will be isothermal in these conditions. To simplify the calculations, we also assumed that ideal gas is compressed ( $\mathrm{R}=$ const.). For the initial position of the pump piston (status indicated by index " 0 ") and at any point in the process, the equation of state can be expressed as

$$
\mathrm{p}_{\mathrm{o}} \cdot \mathrm{V}_{\mathrm{go}}=\mathrm{m}_{\mathrm{go}} \cdot \mathrm{R} \cdot \mathrm{T}_{\mathrm{o}} \text { and } \mathrm{p} \cdot \mathrm{V}_{\mathrm{g}}=\mathrm{m}_{\mathrm{g}} \cdot \mathrm{R} \cdot \mathrm{T},
$$

where $\mathrm{m}_{\mathrm{g}}$ is the mass of gas and $\mathrm{V}_{\mathrm{g}}$ is the part of the volume $\mathrm{V}$ occupied by the gas. The instantaneous $\mathrm{m}_{\mathrm{g}}$ value can be expressed as

$$
\mathrm{m}_{\mathrm{g}}=\mathrm{m}_{\mathrm{go}}-\Delta \mathrm{m}_{\mathrm{g}}
$$

where $\Delta \mathrm{m}_{\mathrm{g}}$ is the mass of gas lost from the volume $\mathrm{V}_{\mathrm{go}}$ due to dissolution at pressure $\mathrm{p}$. By dividing the sides of Equation (15) and taking into Equation (16) after transformation, we obtain

$$
\mathrm{V}_{\mathrm{g}}=\frac{\mathrm{p}_{\mathrm{o}} \cdot \mathrm{V}_{\mathrm{go}}}{\mathrm{m}_{\mathrm{go}}} \cdot \frac{\mathrm{m}_{\mathrm{go}}-\Delta \mathrm{m}_{\mathrm{g}}}{\mathrm{p}},
$$

The amount of gas that got into the solution can be determined with the gas solubility coefficient in liquids $\mathrm{q}\left[\mathrm{g} /\left(100 \mathrm{~g}_{\mathrm{fuel}}\right)\right]$ - it determines the number of grams of gas that dissolves in $100 \mathrm{~g}$ of fuel [25]. According to the tests carried out by Kozak [27], the gas dissolution coefficient in diesel fuel as a function of pressure can be described by an approximate relation in the form $\mathrm{q}=\mathrm{a}_{\mathrm{o}}+\mathrm{a}_{1} \cdot \mathrm{p}+\mathrm{a}_{2} \cdot \mathrm{p}^{2}$. In the case of air, when $\mathrm{a}=0.005$, it can be assumed that this relation is linear in the following form:

$$
\mathrm{q}=0.00125 \cdot \mathrm{p}
$$

The volume $\mathrm{V}_{\mathrm{g}}$ will change according to the following relation:

$$
\mathrm{V}_{\mathrm{g}}=\frac{\mathrm{p}_{\mathrm{o}} \cdot \mathrm{V}_{\mathrm{go}}}{\mathrm{m}_{\mathrm{go}}} \cdot \frac{\mathrm{m}_{\mathrm{go}}-0.00125 \cdot \mathrm{p}}{\mathrm{p}},
$$

The upper integration limit of pressure (pressure value $\mathrm{p}_{\mathrm{z}}$ ) for the compression period at which the entire gas phase enters the solution depends on both the amount of fuel and the amount of gas brought into the analyzed volume. In the case of air, this relation is shown in Figure 3. 


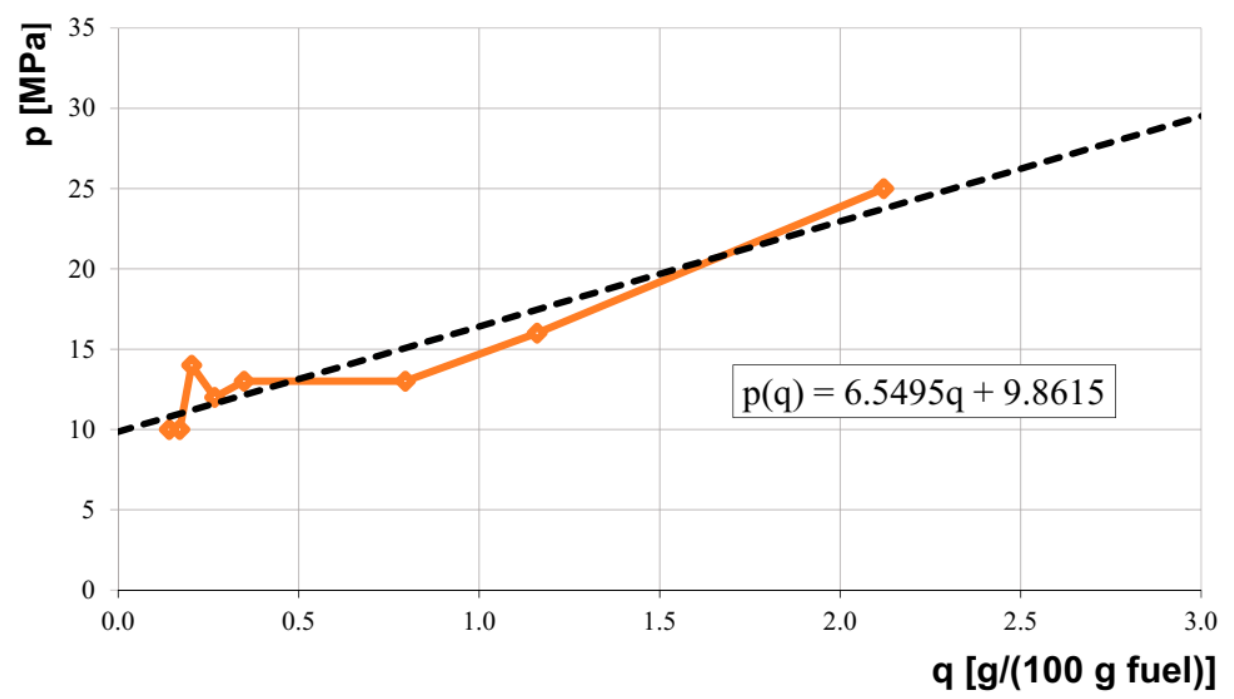

Figure 3. Minimum pressure level necessary for complete dissolution of air (the equation describes the trend line).

A linear simplification was used in further analysis in the form of

$$
\mathrm{p}(\mathrm{q})=6.5495 \cdot \mathrm{q}+9.8615
$$

The absolute mass of air used for atomization support depends on the mass of fuel $\mathrm{m}_{\mathrm{f}}$, which must be supplied to the system to obtain the required torque and the value of adopted $\mathrm{q}$. Thus, theoretically, any value of $\mathrm{m}_{\mathrm{g}}$ can be considered. In practice, however, this value will result from the design of the high-pressure pump $\left(V_{o}\right.$ value of the pump volume) and the pressure in the gas supply. To obtain a change in the amount of gas supplied to the fuel dose $m_{f}$, we need to change the value of $q$. This, of course, will cause a change in the pressure at which the entire gas phase will go into solution as required by the constraints of the pressure Equation (20). This formula shows the pressure value $p_{z^{\prime}}$ which sets the integration limits-for the gas phase, it is the upper integration limit, and for the solution, it is the lower integration limit.

\subsection{Compounds Used to Calculate the Change in Enthalpy}

Taking into account the comments and relations derived in earlier chapters, we can calculate the change in enthalpy during compression from the following relations:

(a) for the pure fuel:

$$
\Delta \mathrm{H}=\mathrm{H}_{2}-\mathrm{H}_{1}=\int_{\mathrm{p}_{\mathrm{o}}}^{\mathrm{p}_{\mathrm{w}}} \mathrm{Vdp}=\frac{\mathrm{V}_{\mathrm{fo}}}{\left(\mathrm{a} \cdot \mathrm{p}_{\mathrm{o}}+\mathrm{b}\right)^{-\frac{1}{a}}} \cdot \int_{\mathrm{p}_{\mathrm{o}}}^{\mathrm{p}_{\mathrm{w}}}(\mathrm{a} \cdot \mathrm{p}+\mathrm{b})^{-\frac{1}{\mathrm{a}}} \mathrm{dp},
$$

where $V_{f o}$ is the initial volume occupied by the fuel in the liquid phase;

(b) for fuel with gas:

(1) phase I for the liquid: The upper integration limit is equal to $p_{z}$. Because the $\mathrm{p}_{\mathrm{z}}$ value is relatively small in comparison to $\mathrm{p}_{\mathrm{w}}, \Delta \mathrm{H}_{\mathrm{c}}$ was calculated as in the case of pure fuel;

(2) phase I for the gas:

$$
\Delta \mathrm{H}=\mathrm{H}_{2}-\mathrm{H}_{1}=\frac{\mathrm{p}_{\mathrm{o}} \mathrm{V}_{\mathrm{go}}}{\mathrm{m}_{\mathrm{go}}} \cdot \int_{\mathrm{p}_{\mathrm{o}}}^{\mathrm{p}_{\mathrm{z}}} \frac{\mathrm{m}_{\mathrm{go}}-0.00125 \cdot \mathrm{p}}{\mathrm{p}} \cdot \mathrm{dp},
$$


where $V_{\text {go }}$ is the volume occupied by the gas, appropriate for the assumed fuel dose and the assumed value of the gas solubility coefficient in the fuel. The total enthalpy increase for phase I is equal to the sum of

$$
\Delta \mathrm{H}_{\mathrm{I}}=\mathrm{H}_{\mathrm{c}}-\Delta \mathrm{H}_{\mathrm{g}},
$$

(3) phase II: there is a solution in the analyzed volume, and the integration limits are lower $-\mathrm{p}_{\mathrm{z}^{\prime}}$ upper $-\mathrm{p}_{\mathrm{w}}$.

$$
\begin{aligned}
& \Delta \mathrm{H}_{\mathrm{II}}=\mathrm{H}_{2}-\mathrm{H}_{1}=\frac{\mathrm{V}_{\mathrm{fo}}}{\left|\frac{\mathrm{a} \cdot \mathrm{p}_{\mathrm{Z}}+\mathrm{b}+\sqrt{\mathrm{b}^{2}-\mathrm{a} \cdot \mathrm{c}}}{\mathrm{a} \cdot \mathrm{p}_{\mathrm{Z}}+\mathrm{b}-\sqrt{\mathrm{b}^{2}-\mathrm{a} \cdot \mathrm{c}}}\right|-\frac{1}{2 \sqrt{b^{2}-a \cdot c}}} \\
& \cdot \int_{p_{z}}^{p_{w}}\left|\frac{a \cdot p+b+\sqrt{b^{2}-a \cdot c}}{a \cdot p+b-\sqrt{b^{2}-a \cdot c}}\right|^{-\frac{p_{z}}{2 \sqrt{b^{2}-a \cdot c}}} d p,
\end{aligned}
$$

and the total enthalpy change will be

$$
\Delta \mathrm{H}=\mathrm{H}_{\mathrm{I}}-\mathrm{H}_{\mathrm{II}}
$$

\subsection{The Numerical Example}

The derived correlations were used to calculate the energy differences between compressing the fuel without gas and compressing the fuel with gas, and with air taken as the gas. The amount of enthalpy to be fed to the fuel during the compression process is calculated for the following example:

(a) in both cases, identical reference conditions were adopted: pressure $\mathbf{p}_{\mathbf{o}}=100,000[\mathbf{P a}]$, temperature $\mathbf{T}_{\mathbf{o}}=293[\mathrm{~K}]$;

(b) in both cases, the fuel dose for one injection is $\mathbf{m}_{\mathbf{f}}=\mathbf{1 0 0}[\mathrm{g}]$, which at the density $\boldsymbol{\rho}=\mathbf{8 3 0}\left[\frac{\mathrm{kg}}{\mathrm{m}^{3}}\right]$ occupies the volume approximately $\mathbf{V}_{\mathrm{fo}}=\mathbf{0 . 0 0 0 1 2}\left[\mathrm{m}^{3}\right]$;

(c) gas solubility coefficient in fuel equals $\mathbf{q}=\mathbf{0 . 0 0 3}\left[\frac{\mathrm{g}}{\mathbf{1 0 0} \mathrm{g} \text { fuel }}\right]$, which, with the assumed fuel dose, determines the mass of air $\mathbf{m}_{\mathrm{go}}=\mathbf{m}_{\mathrm{air}} \cdot \frac{\mathrm{q}}{100}=\mathbf{0 . 0 0 0 1 3}[\mathbf{k g}]$;

(d) the volume occupied by the air mass is $\mathbf{V}_{\text {go }}=\mathbf{0 . 0 0 0 0 0 2 4 6}\left[\mathrm{m}^{3}\right]$ ( calculated from the equation of state for the adopted reference conditions);

(e) up to the adopted value $\mathbf{q}$, the pressure at which the gas phase disappears $\mathbf{p}_{\mathbf{z}}=\mathbf{9 . 8 8}[\mathbf{M P a}]$ is calculated on the basis of the trend lines (20); this value is the upper integration limit for the first part of the compression process, and the lower solution compression limit (without the gas phase) for the second part of the compression;

(f) in both cases, the injection pressure shall equal $\mathbf{p}_{\mathbf{w}}=\mathbf{5 0}[\mathbf{M P a}]$; it is the upper limit of integration for both considered cases;

(g) the following coefficients were adopted to describe the fuel compressibility modulus without air: $\mathrm{a}=13.73, \mathrm{~b}=1444.2$.

\section{Enthalpy Change Calculation Results}

For the adopted example values, the amount of enthalpy that should be introduced during compression is approximately

- for fuel compression without air $-\Delta \mathrm{H}_{\text {fuel }}=7090[\mathrm{~J}]$;

- for solution compression $-\Delta \mathrm{H}_{\mathrm{sol}}=7190[\mathrm{~J}]$;

- for gas phase compression $-\Delta \mathrm{H}_{\mathrm{air}}=10,120[\mathrm{~J}]$.

Thus, the difference in the amount fed during compression of the enthalpy is approximately $\Delta \mathrm{H}=\left(\Delta \mathrm{H}_{\text {sol }}+\Delta \mathrm{H}_{\text {air }}\right)-\Delta \mathrm{H}_{\text {fuel }}=10,150[\mathrm{~J}]$.

With the adopted assumptions, simplifying the obtained result of enthalpy change is undoubtedly not accurate and should be treated as an estimate of energy changes. Nevertheless, it has a very significant value. Due to the introduction of air (in the analyzed case of a small amount), the thermodynamic potential of the injected fuel increased approximately 
1.5 times. This increase is due to the presence of the gas phase, since the enthalpy of the liquid phase hardly changed. Increasing the amount of the gas phase means increasing the thermodynamic potential. Moreover, from the theoretical point of view, gas phase (air mass) used during compression can be of any amount. In order to use the gas release effect from the solution, it must be greater than in the considered example. With the assumed solubility coefficient, the equilibrium pressure reaches the value of $10[\mathrm{MPa}]$, and thus it is comparable to the combustion pressure in naturally aspirated engines and lower than the pressures encountered during the combustion process in supercharged engines. Thus, the stimulus (pressure difference) necessary to trigger the gas release will be relatively weak.

\section{Materials and Methods}

\subsection{Test Stand, Hypocycloidal Pump}

The tests were carried out on a test stand with the AVL 5804 engine (Figure 4). It is a naturally aspirated, single-cylinder diesel engine with direct fuel injection, equipped with a four-valve cylinder head with two camshafts and two independent temperature stabilization systems: lubricating oil and coolant. The engine was not equipped with exhaust gas treatment systems. For the purpose of the analysis, the test stand was equipped with typical systems that enable the measurement of cylinder pressure, pressure before the injector, the course of the voltage that controls the operation of the injectors, pressure in the high-pressure accumulator, and exhaust gas temperature. The signals generated by the sensors of the aforementioned quantities, after conversion into voltage and amplification, together with the signals of the pulses controlling the operation of the injector, were recorded with Indiset 620 (AVL) system.

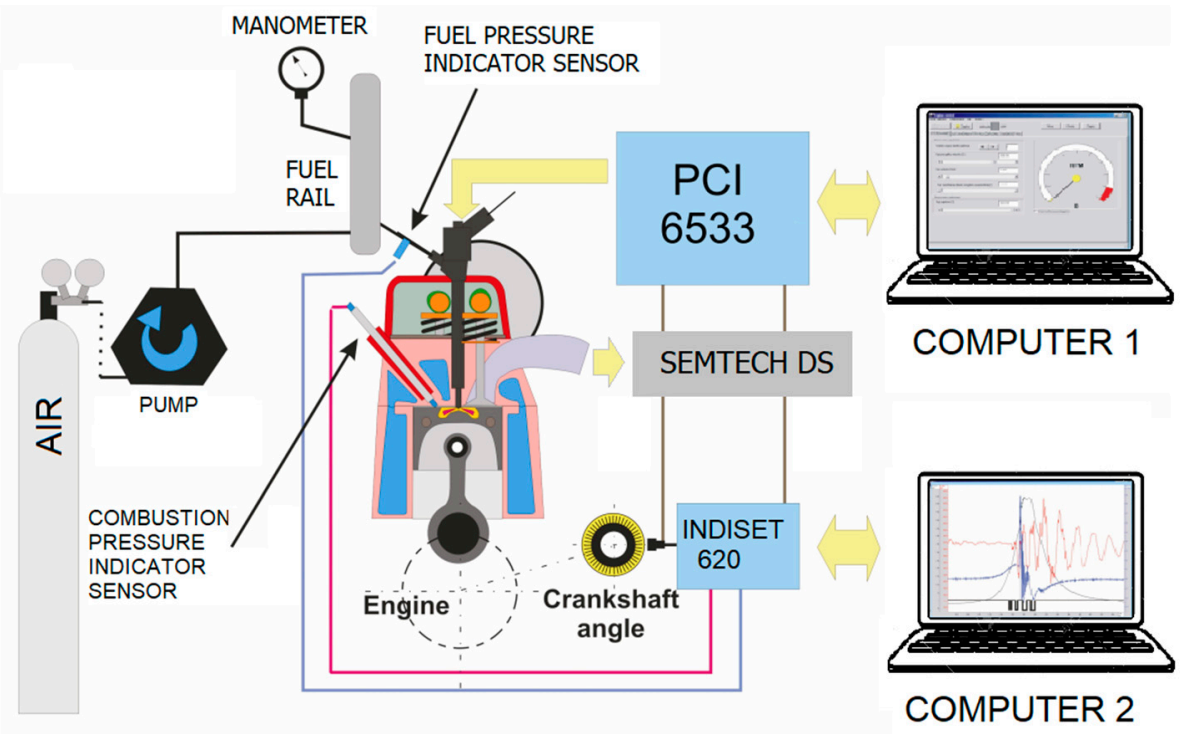

Figure 4. The test stand.

The engine is powered by an autonomous injection system, powered by an electric motor, which includes design parts typical for common rail injection systems.

For the tests, we used a portable exhaust emission analyzer Semtech DS manufactured by Sensors Inc. (Saline, MI, USA). The exhaust sample was taken through a probe and supplied by a heated line maintaining the temperature of $191{ }^{\circ} \mathrm{C}$. Subsequently, the exhaust gases were filtered out of the particulate matter (diesel engine only). Then, the measurement of the concentration of hydrocarbons was carried out in the FID (flame ionization detector). The sample was cooled down to the temperature of $4{ }^{\circ} \mathrm{C}$ and in the NDUV (non-dispersive ultraviolet) analyzer, the measurement of the nitric monoxides and nitric dioxides was performed, and in the NDIR (non-dispersive infrared), the concentration of carbon monoxide is measured. The measurement of oxygen was carried out through an electrochemical sensor. 
Technical data of the Semtech DS device that was used to estimate the errors are presented in Table 1.

Table 1. Technical data of the Semtech DS.

\begin{tabular}{ccc}
\hline Parameter & Measurement Method & Accuracy \\
\hline The concentration of compounds & & \\
$\mathrm{HC}$ & NDIR-non-dispersive, range 0-10,000 ppm & $\pm 3 \%$ \\
$\mathrm{CO}$ & FID-flame ionization, range 0-10,000 ppm & $\pm 2.5 \%$ \\
$\mathrm{NO}_{\mathrm{x}}=\left(\mathrm{NO}+\mathrm{NO}_{2}\right)$ & NDUV-non-dispersive, range 0-3000 ppm & $\pm 3 \%$ \\
$\mathrm{CO}_{2}$ & NDIR-non-dispersive (infrared), range 0-20\% & $\pm 3 \%$ \\
$\mathrm{O}_{2}$ & electrochemical, range 0-20\% & $\pm 1 \%$ \\
Sampling & $1-4 \mathrm{~Hz}$ & \\
Exhaust gas flow & mass flow rate & $\pm 2.5 \%$ \\
\hline & $\mathrm{T}_{\text {max. }}$ up to 700 ${ }^{\circ} \mathrm{C}$ & \\
\hline Supported diagnostic systems & SAE J1850/SAE J1979 (LDV) & \\
& SAE J1708/SAE J1587 (HDV) & \\
\hline
\end{tabular}

The high-pressure pump has an unconventional design. It enables the incoming air to mix with the diesel fuel and to form a solution of diesel fuel with air under high pressure conditions. It was not possible in the research to use pumps that are currently available on the market since most of them use drive shafts with cams. The need to use a high-capacity pump design, i.e., a large stroke of the piston in the delivery section, led us to create a new concept of the injection pump that will be able to meet the requirements. For this purpose, we decided to use a solution with hypocycloid drive [28-34].

The hypocycloid transmission consists of two wheels-the larger (R) wheel had interior toothing, and the smaller ( $\mathrm{r}$ ) wheel had exterior toothing. Torque was applied to the smaller wheel, making it rotate, while the large wheel did not have the ability to rotate along the axis. The smaller wheel moved around the circumference of the larger wheel, and the selected point on the radius of the smaller one drew a curve called a hypocycloid. To induce drive in the pump, we used a hypocycloid gear with a ratio of gear radii $R / r=2$. This selection of wheels made it possible to obtain a resultant rectilinear motion, which resulted from Copernicus' theorem, "If a small circle with a radius half of that of the large circle rotates inside the large circle without slip, then any fixed point on the small circle will move rectilinear along the diameter of the large circle". Figure 5 shows the gearbox operation diagram, along with the straight line marked on which the drive part of the mechanism moved.
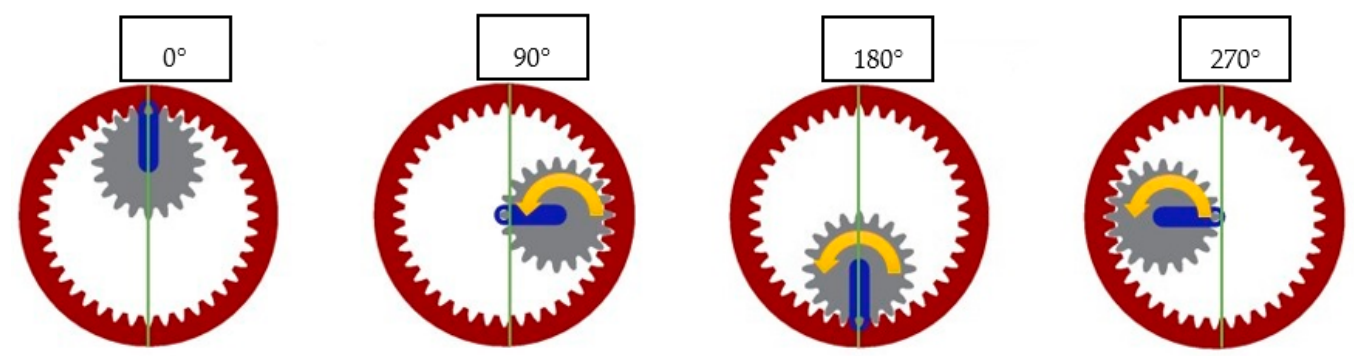

Figure 5. Principle of operation of a hypocycloidal gear.

The analysis of the movement indicates that, like the slider mechanism, it performed a movement in which speed can be described using the sine function. The parametric equation determining the position of a point as a function of the angle of rotation can be determined as follows:

$$
x(\alpha)=(R-r) \cos \alpha+r \cos \left(\frac{R-r}{r} \alpha\right)
$$




$$
x(\alpha)=(R-r) \sin \alpha-r \sin \left(\frac{R-r}{r} \alpha\right),
$$

Taking into account the hypocycloid drive, we created an innovative pump model using Autodesk Inventor software (Figure 6). The pump has been patented. There are many variants of the solution. In the simplest variant equipped with one delivery section, the drive is transmitted to the pump through the main shaft (1). An intermediate shaft (2) is mounted in this shaft in a way that it allows mutual rotation. On the intermediate shaft, there is a gear with exterior toothing, cooperating with the gear (3). The wheel is fixed with screws to the pump body. The drive shaft is mounted on the outer surface of the wheel (3) with a bearing. The intermediate shaft has an eccentric shaft (4) on which the piston (plunger) (5) and the guide element are mounted, which are slidably positioned in the cylinder. In addition, the intermediate shaft has a support (6) mounted in the pump body with a bearing.

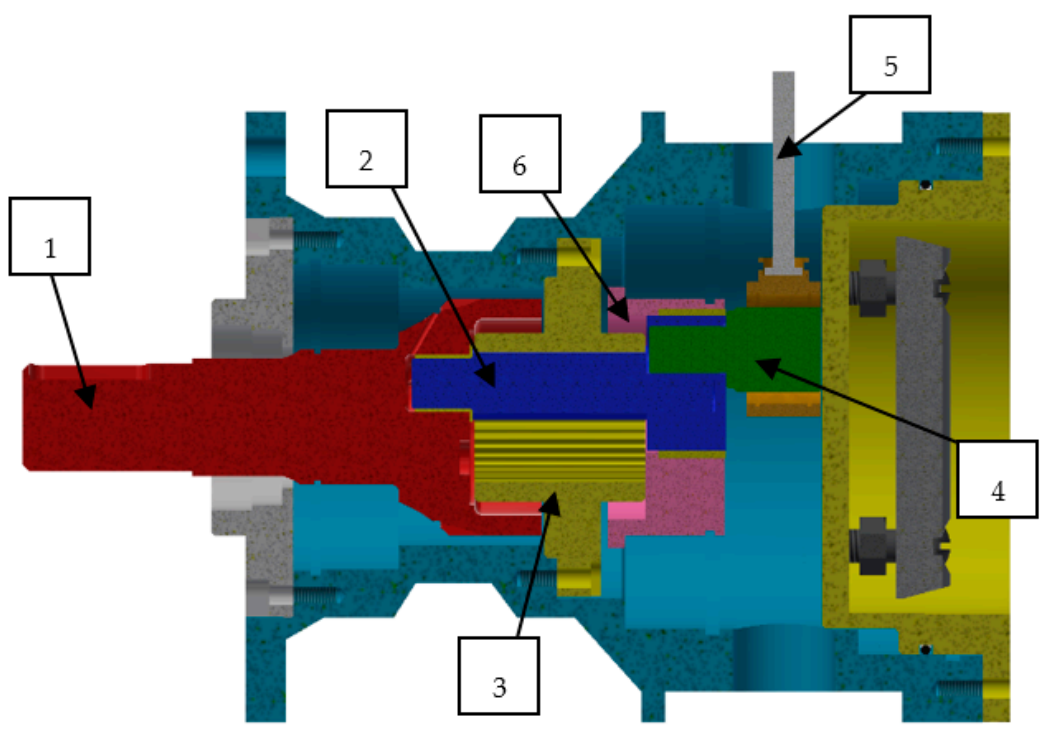

Figure 6. Cross-section of model of a high-pressure hypocycloid drive pump with the assumed simplifications: 1-main shaft, 2-intermediate shaft, 3-gearing with internal meshing, 4-mandrel, 5 - piston (plunger), 6-intermediate shaft support.

The authors' main goal was to propose a solution that would meet the requirements for using the gas desorption effect from the solution with nucleation of gas bubbles. Therefore, the proposed pump model for a tooth module equal to $1 \mathrm{~mm}$ and a number of teeth equal to 40 has an actuator stroke of $40 \mathrm{~mm}$. A large pitch of the operating element, equal to the pitch diameter of the large gear, is undoubtedly the advantage of the proposed solution. A characteristic feature of the hypocycloid drive used in the model has a precisely defined gear ratio, which must equal exactly 2. Moreover, for the mechanism to convert rotary motion into rectilinear, it is also necessary to use an even number of teeth.

There are more benefits of using a hypocycloid drive. One of them is the elimination of lateral forces on the piston of the pump pressure section. The use of the hypocycloid mechanism also allows for increasing the pump resistance to difficult fuels-in the pump construction presented, the delivery section was separated from the drive system, assuming its lubrication with engine or transmission oil. Due to the large piston stroke, and hence the length of the pressure section, it is possible to use a double labyrinth seal, together with a channel for draining leaking fuel to the injector overflow line. This will allow a minimum, acceptable leaking of diesel fuel to the lubricating fluid. The advantageous features of the pump also include the lack of a return spring. Pump solutions using a cam system for each section have a return spring, ensuring constant pressure of the pusher on the cam. In addition to the obvious increase in the mass of the system, the spring is an element that receives energy 
and gives it away in the form of heat to a small extent. In addition, due to a large number of cycles, return springs are susceptible to damage associated with material fatigue.

During the tests, the values of the basic injection parameters, i.e., the angle of the start of injection and the duration of injection (it determines the dose of the injected fuel) were determined by means of an electronic fuel injection control system built especially for the research purposes. The control system was coupled with the engine by signals from two sensors: an RPM (revolutions per minute) sensor associated with the engine crankshaft and a phase sensor associated with the camshaft. The injection pressure (pressure in the accumulator) was set by changing the rotational speed of the motor driving the highpressure pump and the relief valve mounted on the high-pressure accumulator.

\subsection{Method of Analysis and Research Program}

In the first case, the engine was powered by an injection system that uses a conventional fuel injection mechanism. In the second case of the tests, the engine was powered by a system using the desorption effect. The evaluation of the impact of the desorption effect on the combustion process was made on the basis of a comparative analysis of the initial quantities, which capture the energy effects, the relationship of which with the injection mechanism is unambiguous, but it is neither direct nor easy to be analyzed analytically. In both cases, the tests were performed in identical engine operating conditions.

The following values were considered for the comparative analysis:

- indicated pressure course $P_{c}$;

- the pressure increase rate $d P_{c} / d \alpha$ and its maximum value $d P_{c} / d \alpha_{\max }$;

- maximum combustion pressure $P_{c} \max$;

- injection pressure $P_{i n j}$;

- the combustion time span defined by combustion angle $\alpha$;

- heat release rate $\Delta X_{i} / \Delta \alpha$ its maximum value $\Delta X_{i} / \Delta \alpha_{\max }$ and the amount of released heat $X_{i}$;

- injection time $t_{\text {inj; }}$;

- $\quad$ engine torque $E T$;

- the emissions of $\mathrm{PM}$ - particulate matter, $\mathrm{CO}, \mathrm{HC}$, and $\mathrm{NO}_{x}$-nitrogen oxides at the exhaust gas components measuring points.

When establishing the test program, we assumed that the above-mentioned quantities would be measured at the engine operating points, representing the average values of rotational speed and torque, and the obtained results would allow for the assessment of the overall general characteristics. Following this assumption, the crankshaft rotational speed was selected from the range of operation of AVL 5804 engine (without supercharging) - $2000 \mathrm{rpm}$, at which the engine was loaded with a torque equal to $E T=5,10,15$, and $20 \mathrm{~N} \cdot \mathrm{m}$.

For a specific nozzle design, the injection pressure determines the structure of the fuel stream atomization. In injection systems used today, the injection pressure often exceeds the value of $200 \mathrm{MPa}$. While developing the discussed concept, we assumed that the changes in the pump design are worth effort if and only if the injection structure equivalent to that of a conventional system would be obtained at a much lower injection pressure. Taking this assumption into account, we decided to perform the injection at extremely low pressure in the high-pressure accumulator, amounting to $35 \mathrm{MPa}$.

The mass of air dissolved in diesel fuel was controlled by changing the supply pressure of the high-pressure pump. Measurements were made at ambient pressure $p=0$ [bar] and overpressure $p_{\text {air }}$ equal to: 1,3 and 5 [bar].

\section{Results and Discussion}

The engine test results are presented in the form of graphs marked with indices and symbols identifying the analyzed test case. All measurement results obtained in the first series of tests (the case of fueling the engine with diesel oil without air) are marked with the index on the graphs $k$. The results marked with index $k$ were obtained on the basis of the tests performed with a conventional injection pump (Bosch CP1). On the other hand, 
the digits in the description of the figure reflect the overpressure of the air that supplies the high-pressure pump $p 1, p 3, p 5$.

The qualitative nature of changes $P_{c}$ in the courses $d P_{c} / d \alpha$ of function of the angle of rotation of the crankshaft, resulting from the introduction of air into the diesel fuel and supplying the engine with a solution, is shown on the example of measurements made for a load with a constant torque, $E T=15[\mathrm{~N} \cdot \mathrm{m}]$ for a set engine speed equal to $n=2000 \mathrm{obr} / \mathrm{min}$. These changes are illustrated in Figure 7, which also shows the injection pressure $P_{i n j}$ (in the fuel tank) and the signal $t_{i n j}$ that controls the opening of the injector.
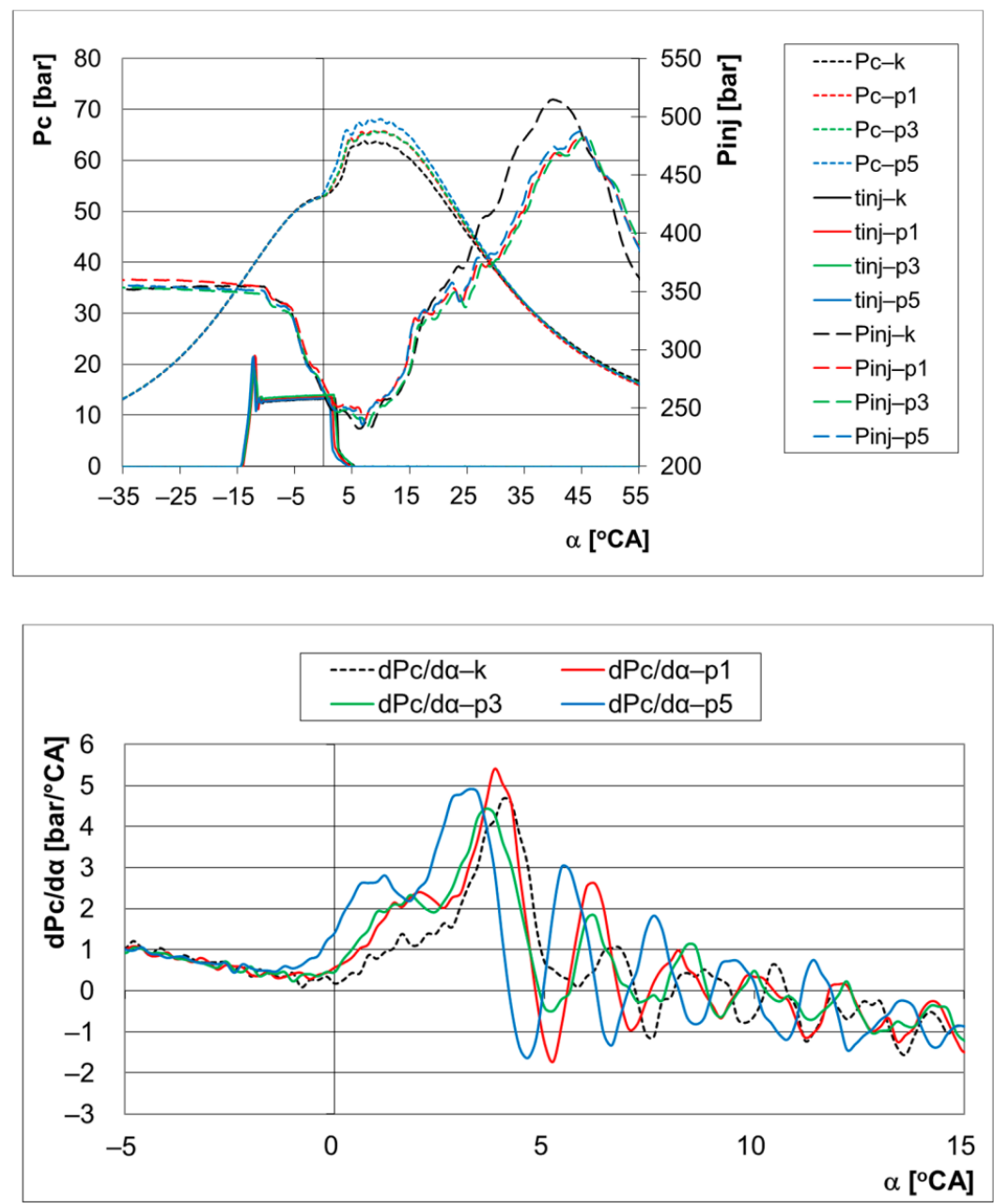

Figure 7. The waveform of the time signal $t_{i n j}$ that controlled the injector, pressure $P_{i n j}$ in the accumulator, pressure $P_{\mathcal{C}}$ in the cylinder, and the rate of pressure rise $d P_{c} / d \alpha$ under engine load $E T=15[\mathrm{~N} \cdot \mathrm{m}]$.

Compared to a conventional power system, the presence of air in the fuel always caused a slight increase in value $P_{c}$ and significant changes in the course $d P_{c} / d \alpha$. At the beginning of combustion, the instantaneous values $d P_{c} / d \alpha$ increased and at the same time its maximum value decreased. Moreover, an $d P_{c} / d \alpha$ additional maximum (the first peak) began to appear on the waveform and its value increased with the increase in engine speed. Thus, the waveform $d P_{c} / d \alpha$ was flattened, which was visible. However, this trend was more apparent with air supply overpressure $p_{\text {air }}=5[\mathrm{bar}]$. This result suggests that at lower pressure, the mass of dissolved air was too small to fully reveal the desorption effect. The figures also show the tendency to shorten the auto-ignition delay period, which increased with the increase of dissolved air mass. 
The quantitative presentation of changes in the analyzed parameters is presented in the following figures. Figure 8 shows influence of air supply pressure $p_{\text {air }}$ on maximum combustion pressure $P_{c \text { max }}$. The desorption effect always caused an increase $P_{c \max }$ in value compared to conventional fueling, and it increased throughout the entire area of the engine operation with the increase of the mass of air dissolved in the fuel; however, it was negligible because it did not exceed a few percentages.

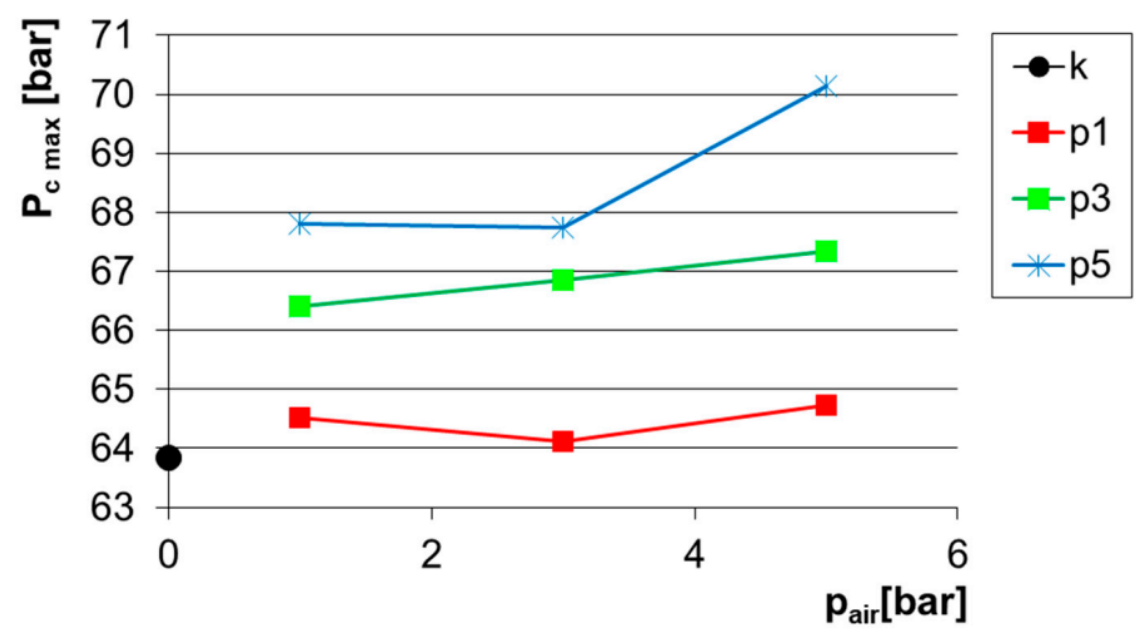

Figure 8. Influence of air supply pressure $p_{\text {air }}$ on maximum combustion pressure $P_{c \text { max }}$.

The research proved that the desorption effect did not significantly change the burning period $\alpha$. However, there was a clearly noticeable change in the dynamics of the X curve reaching the value of 0.999 (Figure 10). As the mass of dissolved air increased, reaching this value, it became more and more asymptotic. This means that more fuel was burned in the initial phase of the process. Thus, the amount of fuel burned in the final phase decreased, and the burning time of this amount remained approximately constant. In line with this trend, the energy effects were also diminished. It seemed that such a state may have been caused not only by the atomization structure (the diameter of fuel droplets and the evaporation rate limit the amount of fuel ready for combustion), but also by the concentration of substrates (local lack of oxygen), which was determined by the internal mass transport mechanism.

The desorption effect is clearly visible on the maximum values of the pressure build-up rate $d P_{c} / d \alpha_{\max }$ in the cylinder, as shown in Figure 9 . This parameter shows a downward tendency, especially in the case of speed characteristics.

During fuel injection at $p_{\text {air }}=5[\mathrm{bar}] n=2000[\mathrm{rpm}]$, and $E T=15[\mathrm{~N} \cdot \mathrm{m}]$ compared to conventional injection, the reduction $d P_{c} / d \alpha_{\max }$ was about $25 \%$. This result, especially in conjunction with the course $P_{c \text { max }}$, indicates that the maximum value of the pressure in the cylinder, primarily $d P_{c} / d \alpha$, affected the course and not its maximum value. The changes in the $d P_{c} / d \alpha$ course of the function, shown in Figure 7 , took place in such a direction that despite the lowering of the maximum value $d P_{c} / d \alpha_{\max }$, the combustion rate increased compared to conventional fueling, especially at the beginning of combustion. Most likely, the increase in the combustion rate under these conditions was due to the simultaneous overlap of a slight extension of the auto-ignition delay period and the resulting increase in fuel accumulation in this period, with the adjustment of the spray structure (shape and range of the stream) to the charge movement in the combustion chamber. Increasing the maximum value proved that from the point of view of the kinetics of chemical reactions, this adjustment was the most favorable. 


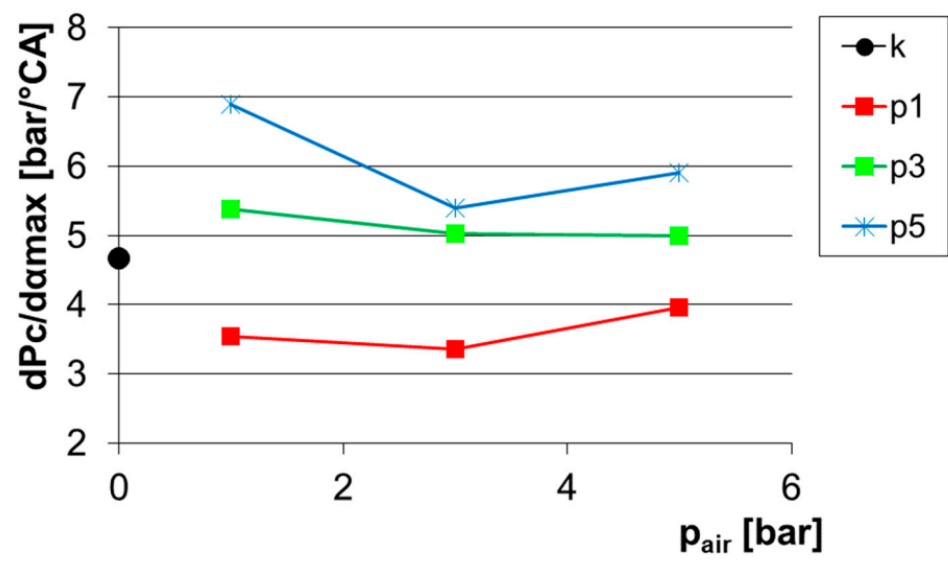

Figure 9. Effect of air supply pressure $p_{\text {air }}$ on $d P_{c} / d \alpha_{\max }$.

Important data for the evaluation of the described mechanism resulted from the analysis of the course of heat release. Figure 10 shows the course of the heat release rate $\Delta X_{i} / \Delta \alpha$, the heat $X_{i}$ absorbed by the exhaust gas, and the average temperature $T_{g}$ of the exhaust gas in the cylinder.
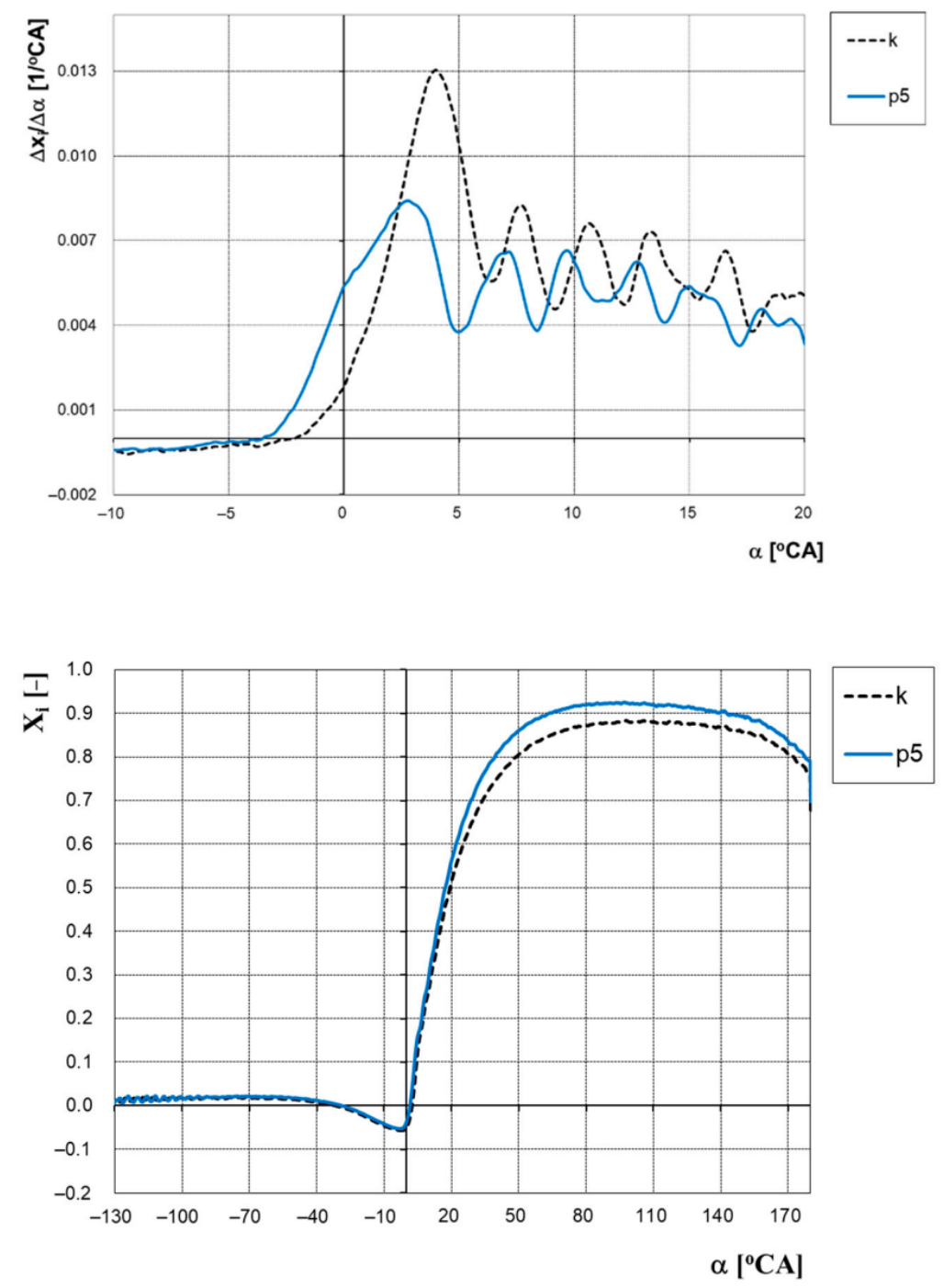

Figure 10. Conts. 


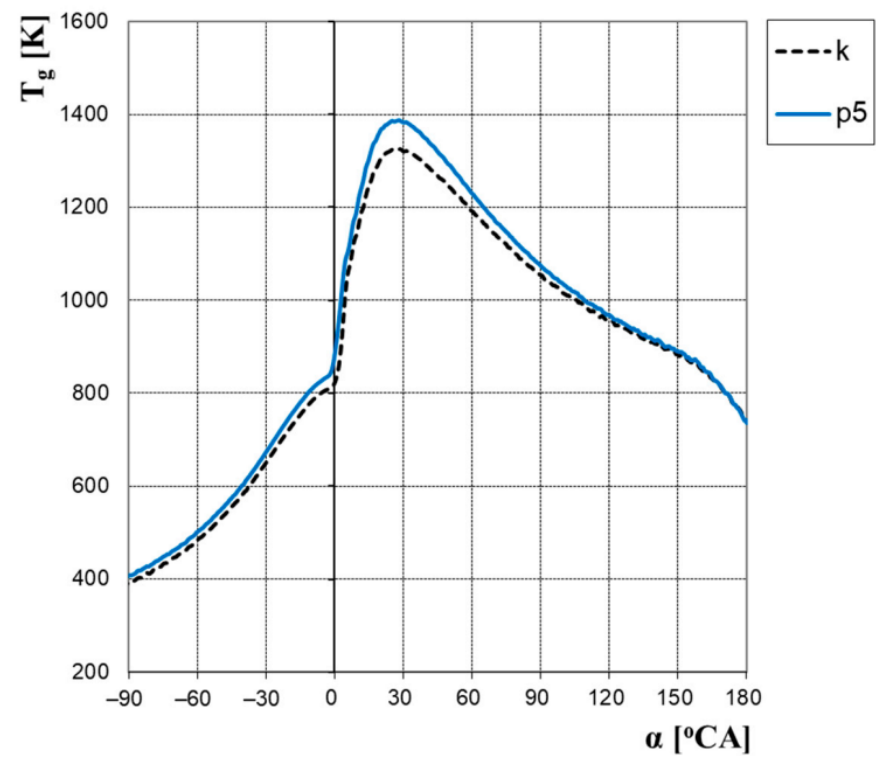

Figure 10. The course of the rate of heat $\Delta X_{i} / \Delta \alpha$ release, the heat absorbed by the exhaust gas $X_{i}$, and the average temperature $T_{g}: E T=15[N \cdot m]$ of the exhaust gas $(n=2000[\mathrm{rpm}])$.

The calculations assumed that the specific heat of air and exhaust gas was a linear function of temperature over the entire temperature range during combustion. The temperature of the exhaust gas necessary to calculate the specific heat was calculated assuming that the fuel burnout was consistent with the Wiebe function, and the exponent of this function was constant and equal to 1.59. The burn-end angle was determined on the basis of the course of the polytrope exponent. In order to make the image more comprehendible, we limited the number of curves presented in the figures to only two extreme test cases-for conventional injection and air injection $p_{\text {air }}=5$ [bar].

Compared to conventional fueling, the maximum value of the $\Delta X_{i} / \Delta \alpha$ kinetic combustion phase was significantly reduced, the course of the function was shifted to the left, and the diffusion combustion period was clearly marked. However, in the final part of the diffusion combustion phase, the differences were unnoticeable. According to the first law of thermodynamics, the course $\Delta X_{i} / \Delta \alpha$ directly affected the curves $X_{i}$ and $T_{g}$, i.e., the increase in value $\Delta X_{i} / \Delta \alpha$ was accompanied by an increase in the value of both these quantities. Increasing the rate of growth $\Delta X_{i} / \Delta \alpha$ in the initial combustion phase and reducing its maximum value indicated a better preparation of the fuel for combustion and a reduction in fuel accumulation in the period of auto-ignition delay. This indicated a better coupling of the combustion process with the fuel feeding course, at least in the initial phase of the process. At low engine speed and low load, the course of $X_{i}$ air-fuel solution was above that of conventional fueling. As the engine speed and/or workload increased, these curves began to intersect at the end of combustion. This means that in the case of conventional fueling, the energy processes related to the combustion of fuel were stronger than in the case of solution-based fueling.

The change in the injection mechanism caused by the desorption effect was much more visible on the example of changes in the exhaust gas composition, as shown in Figures 11-14. They show the results of measurements of $\mathrm{PM}, \mathrm{CO}, \mathrm{HC}$, and $\mathrm{NO}_{\mathrm{x}}$ emissions from the AVL 5804 engine. The desorption effect was used in the engine, and the results were presented as a function of the torque for the solution-based fueling (three values of air overpressure $p_{\text {air }}=1,3,5$ [bar]) compared to the conventional fueling, which was the reference system $(100 \%)$. 


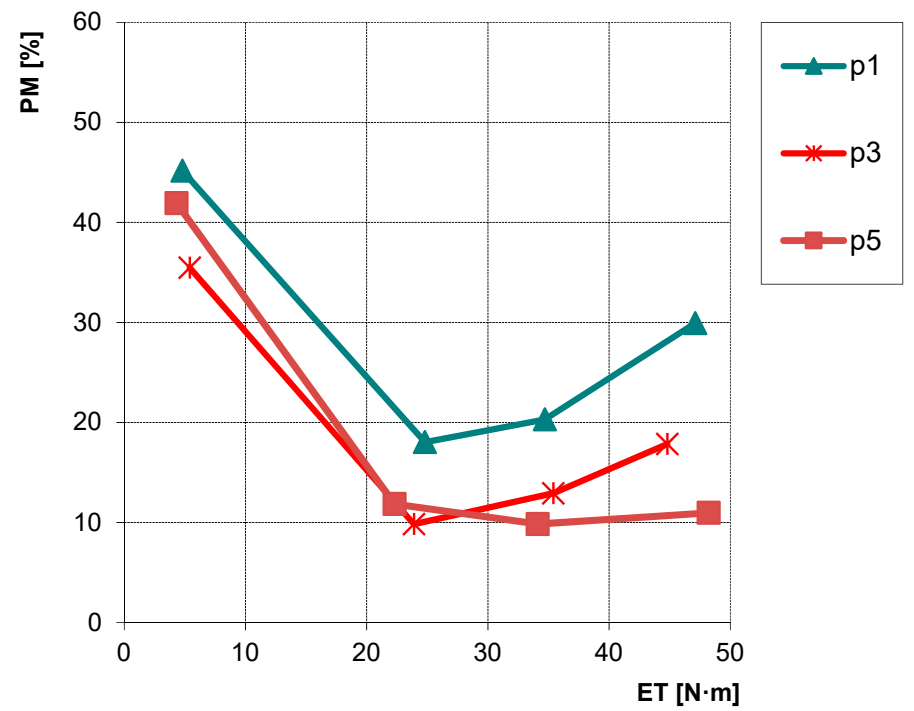

Figure 11. Changes in PM emissions under load characteristics.

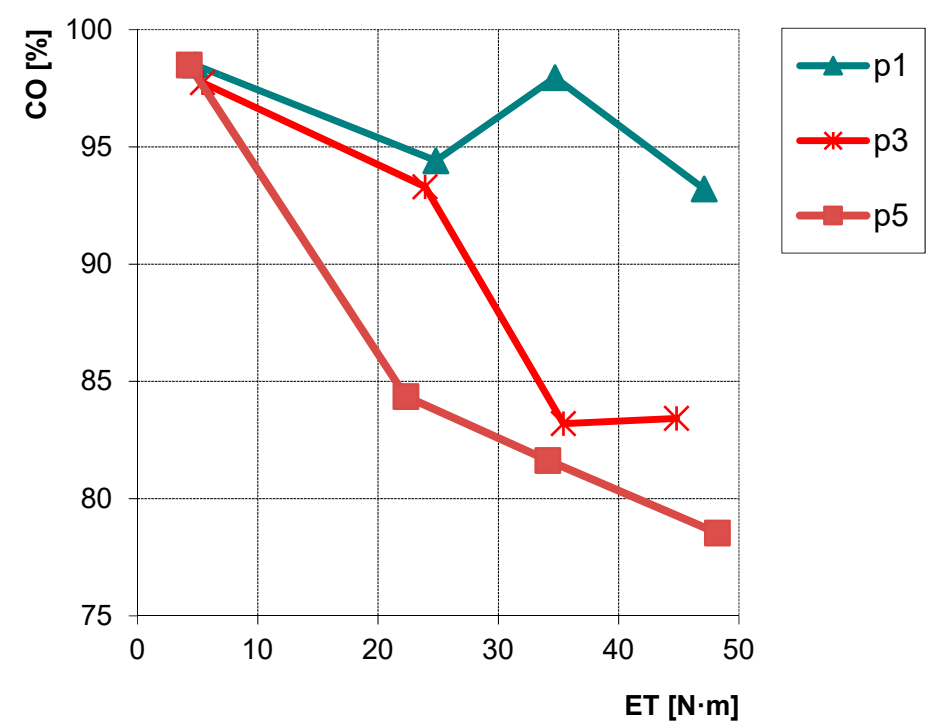

Figure 12. Changes in $\mathrm{CO}$ emissions under load characteristics.

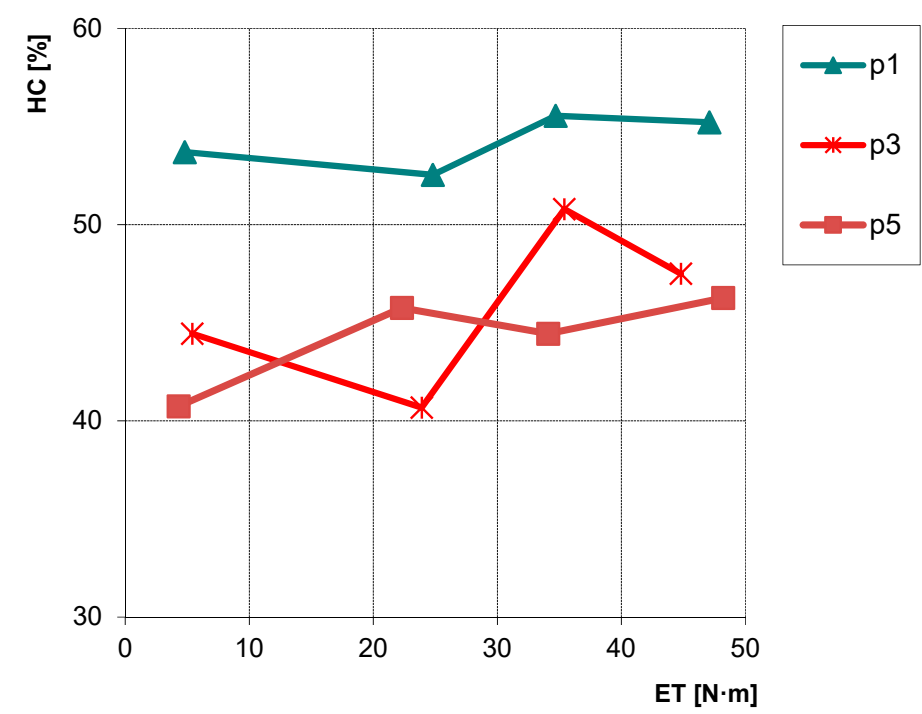

Figure 13. Changes in HC emissions under load characteristics. 


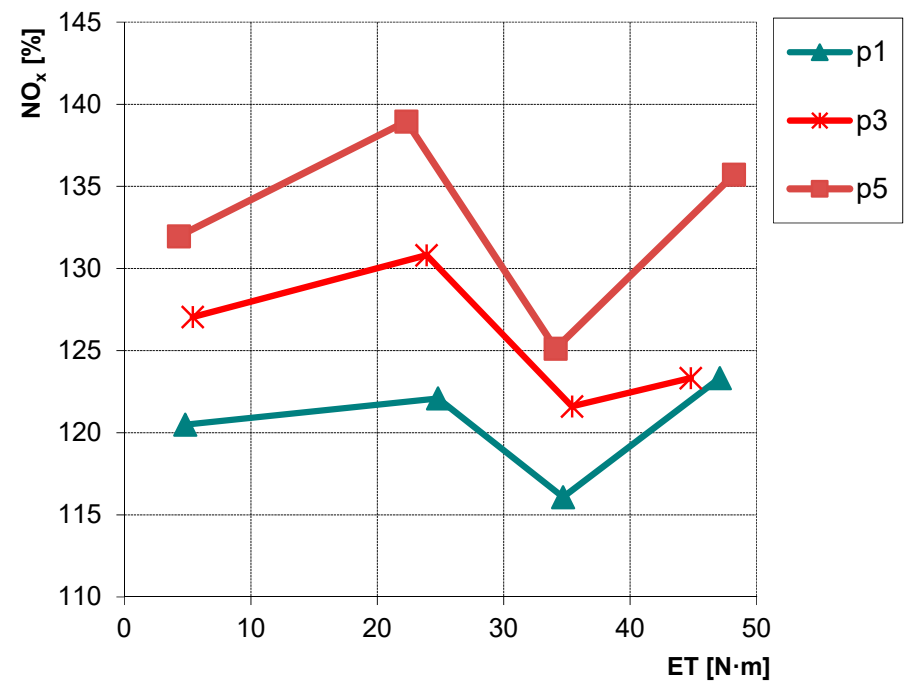

Figure 14. Changes in $\mathrm{NO}_{\mathrm{x}}$ (nitrogen oxides) emissions under load characteristics.

The effect of the desorption effect on PM emissions is shown in Figure 11. In each test case, a significant reduction in emissions was observed, depending on the engine operating conditions. The tendency to reduce PM emissions increased with the increase in the amount of air dissolved in the fuel, especially in the range of low rotational speed and high torque. For high loads, the reduction in emissions was up to $90 \%$, which should be considered an excellent result.

Substantial changes in $\mathrm{CO}$ emissions were also observed during the tests, as shown in Figure 12. On the basis of the obtained results, we can conclude that the desorption effect caused, in general, a reduction in emissions, in the case of PM alike, especially in the area of high engine load. The reduction in emissions became greater with the increasing amount of dissolved air. The maximum reduction for $n=2000 \mathrm{obr} / \mathrm{min}$ air speed and overpressure $p_{\text {air }}=5$ [bar] was more than $20 \%$.

The results of HC emission measurements shown in Figure 13 allow for an unambiguous assessment of the desorption effect. In the entire area of the engine operation, we observed a significant reduction in emissions, with this tendency increasing along with the increase in engine load and the increase in the amount of dissolved air. For example, at the highest torque $n=2000[\mathrm{rpm}]$ and pressure values $p_{\text {air }}=5$ [bar], the emissions were twice as low.

Should the improvement of the injection structure be solely accounted for the reduction in $\mathrm{PM}$ and $\mathrm{HC}$ when the engine was supplied with a solution, an increase in $\mathrm{NO}_{\mathrm{x}}$ emissions would be expected. The results of $\mathrm{NO}_{\mathrm{x}}$ measurements presented in Figure 14 clearly confirm this presupposition. At almost all measuring points, an increase in $\mathrm{NO}_{x}$ emissions was recorded. The emission significantly increased together with the amount of dissolved air within the range of low engine speed. In the following example $n=2000[\mathrm{rpm}]$, the load-dependent increase in emissions was from about $15 \%$ to about $40 \%$.

The presented emission results of the analyzed exhaust gas components were a function of indirect measurements such as concentration of components in the exhaust gas [ppm], $\mathrm{G}_{\mathrm{p}}$ exhaust stream $[\mathrm{kg} / \mathrm{h}]$, exhaust gas humidity [\%], $\mathrm{n}$ rotational speed [rpm], and ET engine torque $[\mathrm{Nm}]$. In the case of indirect measurement of the quantity $w$, which is a function of several component quantities $x_{i}$, i.e.,

$$
\mathrm{w}=\mathrm{f}\left(\mathrm{x}_{1}, \mathrm{x}_{2}, \ldots, \mathrm{x}_{\mathrm{n}}\right)
$$

the error $(\Delta \mathrm{w})$ of the indirectly measured quantity is determined, where the value of this error depends on the errors $\left(\Delta_{\mathrm{xi}}\right)$ of the component quantities and their mutual relationship.

The function $(w)$ can be written as

$$
\mathrm{w}=\mathrm{f}\left(\mathrm{x}_{1}+\Delta \mathrm{x}_{1}, \mathrm{x}_{2}+\Delta \mathrm{x}_{2}, \ldots \mathrm{x}_{\mathrm{n}}+\Delta \mathrm{x}_{\mathrm{n}}\right)
$$


According to the error transfer law, after expanding the function into the Taylor series, the obtained formula allows for calculation of the so-called maximum error:

$$
\Delta \mathrm{w}= \pm\left(\sum_{\mathrm{i}=1}^{\mathrm{n}}\left|\frac{\partial \mathrm{f}\left(\mathrm{x}_{1}, \mathrm{x}_{2}, \ldots, \mathrm{x}_{\mathrm{n}}\right)}{\partial \mathrm{x}_{\mathrm{i}}}\right| \Delta \mathrm{x}_{\mathrm{i}}\right)
$$

The assumption of summing up the components of the formula leads to overestimating the value of this error, because the probability of actual summation of the maximum values of errors in component quantities is small.

In the special case when the quantity $\mathrm{w}$ is given in an equation such as

$$
\mathrm{w}=\mathrm{A} \prod_{\mathrm{i}=1}^{\mathrm{n}} \mathrm{x}_{\mathrm{i}}^{\mathrm{a}_{\mathrm{i}}}
$$

it is easier to determine the relative error of measurement:

$$
\left|\frac{\Delta w}{w}\right|=\sum_{i=1}^{n}\left|a_{i} \frac{\Delta x_{i}}{x_{i}}\right|
$$

Below, Table 2 presents the analysis of measurement errors according to the uncertainty transfer law for an exemplary measurement when $p_{\text {air }}=5$ [bar].

Table 2. Analysis of measurement errors according to the uncertainty transfer law (example for $\left.p_{\text {air }}=5[\mathrm{bar}]\right)$

\begin{tabular}{ccccc}
\hline \multicolumn{5}{c}{$p_{\text {air }}=5[$ bar $]$} \\
\hline ET [N.m] & PM [\%] & CO [\%] & HC [\%] & NO $_{\mathbf{x}}[\%]$ \\
\hline 4.3 & $41 \pm 14$ & $98 \pm 8$ & $40 \pm 9$ & $131 \pm 11$ \\
\hline 22.3 & $11 \pm 15$ & $84 \pm 7$ & $45 \pm 8$ & $138 \pm 10$ \\
\hline 34.1 & $9 \pm 13$ & $81 \pm 11$ & $44 \pm 11$ & $125 \pm 12$ \\
\hline 48.2 & $10 \pm 14$ & $78 \pm 12$ & $46 \pm 13$ & $135 \pm 13$ \\
\hline
\end{tabular}

\section{Conclusions}

The paper presents theoretical foundations of the concept of supporting the process of fuel injection in an internal combustion engine with the effect of gas desorption from a solution with nucleation of gas bubbles. On the basis of the presented considerations, we can draw a basic conclusion: the described mechanism of the effect of gas desorption is a concept that improves the operation of the engine, as demonstrated by the results of selected operating parameters and harmful emissions.

The presented thermodynamic analysis, based on the example provided, shows that mixing gas with fuel (in the analyzed case a small amount of air) increased the thermodynamic potential of the injected fuel approximately 1.5 times. This increase was due to the presence of the gas phase, since the enthalpy of the liquid phase hardly changed. Moreover, from the theoretical point of view, gas phase (air mass) used during compression can be of any amount. We also showed the results of searching for the minimum pressure required to obtain the saturation state of the fuel and air solution depending on the mass of the dissolved air.

It should be noted that the ambient pressure of the droplets (prevailing in the combustion chamber) was by definition much lower than the pressure of the equilibrium state of the solution in the injection system. Therefore, a non-equilibrium stimulus must occur to initiate the release of gas from the solution. If we consider the fact that this process took place within a fuel drop, in which the liquid phase was held by relatively subtle forces (surface tension), only one conclusion can be drawn. The process of releasing the gas from the droplets must be as described, i.e., it must facilitate the breakdown of the fuel droplets 
and thus improve the atomization structure, and by doing so have a positive effect on the engine operation.

This was proven in the results section. The results confirmed a significant reduction in PM-at high loads, the reduction was up to $90 \%$. For CO emission measurements, the emission reduction oscillated around $20 \%$ for high loads. In turn, HC emissions were reduced by about half. Although $\mathrm{NO}_{x}$ emissions increased, the results of $\mathrm{PM}, \mathrm{CO}$, and $\mathrm{HC}$ emission measurements improved significantly, which confirms the very favorable effect of the desorption effect on engine operation and emissions.

A very important conclusion is that the desorption effect was obtained at much lower injection pressures in relation to the pressures found in common rail systems. The use of the effect helped to relieve the mechanical load on the injection system components, which in turn may translate into increased reliability of high-pressure pumps.

The disadvantage of the concept is the need to use custom injection pumps that are able to dissolve gas in diesel fuel. The proposed new design meets these requirements. First of all, it has a much larger piston stroke, which in the proposed solution is $40 \mathrm{~mm}$. The design also has a number of additional advantages such as elimination of lateral forces in the piston-cylinder arrangement of the compression section. In addition, the delivery function has been separated from the lubrication function-the pump components are lubricated with gear oil, and not, as in most solutions, pumped by diesel oil.

\section{Patents}

W. Karpiuk, R. Smolec, and T. Borowczyk, "High-pressure engine-feeding pump", patent no. PL232500, (2018), in Polish.

Author Contributions: Conceptualization, M.B. and W.K.; methodology, M.B. and W.K.; software, W.K. and R.S.; validation, M.B., W.K., and R.S.; formal analysis, M.B. and W.K.; investigation, M.B., W.K., and R.S.; resources, M.B., W.K., and R.S.; data curation, W.K. and R.S.; writing—original draft preparation, W.K. and M.B.; writing-review and editing, W.K.; visualization, W.K.; supervision, W.K. and M.B.; project administration, W.K.; funding acquisition, W.K. All authors have read and agreed to the published version of the manuscript.

Funding: National Centre for Research and Development, Poland: Lider/015/273/L-5/13/NCBR/2014.

Institutional Review Board Statement: Not applicable.

Informed Consent Statement: Not applicable.

Data Availability Statement: The data presented in this study are available on request from the corresponding author.

Conflicts of Interest: The authors declare no conflict of interest.

\section{References}

1. Bowman, C.T. Kinetics of pollutant formation and destruction in combustion. Prog. Energy Combust. Sci. 1975, 1, 33-45. [CrossRef]

2. Chakraborty, B.B.; Long, R. The formation of soot and polycyclic aromatic hydrocarbons in diffusion flames. Combust. Flame 1968, 12, 469-476. [CrossRef]

3. Reksowardojo, I.K.; Setiapraja, H.; Fajar, R.; Wibowo, E.; Kusdiana, D. An investigation of laboratory and road test of common rail injection vehicles fueled with B20 biodiesel. Energies 2020, 13, 6118. [CrossRef]

4. Ge, J.C.; Choi, N.J. Soot particle size distribution, regulated and unregulated emissions of a diesel engine fueled with palm oil biodiesel blends. Energies 2020, 13, 5736. [CrossRef]

5. Zhang, J.; Yang, F. In-cycle real-time prediction technology of $\mathrm{NO}_{\mathrm{x}}$ emission of diesel engines based on cylinder pressure. SAE Int. J. Engines 2014, 7, 1084-1092. [CrossRef]

6. Jedlinski, L.; Caban, J.; Krzywonos, L.; Wierzbicki, S.; Brumerčík, F. Application of the vibration signal in the diagnosis of the valve clearance of an internal combustion engine. J. Vibroeng. 2015, 17, 175-187.

7. Maennel, A.; Kim, H.-G. Comparison of greenhouse gas reduction potential through renewable energy transition in South Korea and Germany. Energies 2018, 11, 206. [CrossRef]

8. Czyż, Z.; Grabowski, Ł.; Pietrykowski, K.; Czarnigowski, J.; Porzak, M. Measurement of flight parameters in terms of toxic emissions of the aircraft radial engine ASz62-IR. Measurement 2018, 113, 46-52. [CrossRef] 
9. Kokota, H.; Kosaka, H.; Tsujimura, K.; Kamimoto, T. Fast burning and reduced soot formation via ultra-high pressure diesel fuel injection. SAE Tech. Pap. Ser. 1991, 910225, 1-9. [CrossRef]

10. Li, Z.; Kokkolaras, M.; Jung, D.; Panos, Y.; Assanis, D. An optimization study of manufacturing variation effects on diesel injector design with emphasis on emissions. SAE Tech. Pap. Ser. 2004, 2004-01-1560, 1-12. [CrossRef]

11. Minato, A.; Tanaka, T.; Nishimura, T. Investigation of premixed lean diesel combustion with ultra high pressure injection. SAE Tech. Pap. 2005, 2005-01-0914, 1-11. [CrossRef]

12. Nagata, K. State-of-art technologies for diesel common rail system. SAE Tech. Pap. Ser. 2004, 2004-28-0068, 442-446. [CrossRef]

13. Yoon, S.K.; Ge, J.C.; Choi, N.J. Influence of fuel injection pressure on the emissions characteristics and engine performance in a CRDI diesel engine fueled with Palm biodiesel blends. Energies 2019, 12, 3837. [CrossRef]

14. Meek, G.; Williams, R.; Thornton, D.; Knapp, P.; Cosser, S. F2E-ultra high pressure distributed pump common rail system. SAE Tech. Pap. Ser. 2014, 2014-01-1440, 1-8. [CrossRef]

15. Matsumoto, S.; Yamada, K.; Date, K. Concepts and evolution of injector for common rail system. SAE Tech. Pap. Ser. 2012. [CrossRef]

16. Wloka, J.; Pflaum, S.; Wachtmeister, G. Potential and challenges of a 3000 bar common-rail injection system considering engine behavior and emission level. SAE Int. J. Engines 2010, 3, 801-813. [CrossRef]

17. Mata, C.; Piaszyk, J.; Soriano, J.A.; Herreros, J.M.; Tsolakis, A.; Dearn, K. Impact of alternative Paraffinic fuels on the durability of a modern common rail injection system. Energies 2020, 13, 4166. [CrossRef]

18. Merkisz, J.; Bajerlein, M.; Kozak, W. Dissolving oxygen in diesel fuel as a way to make road transport more environmentally friendly. Urban Transp. XIV 2008, 101, 325-334. [CrossRef]

19. Merkisz, J.; Kozak, W.; Bajerlein, M.; Markowski, J. The influence of exhaust gases dissolved in diesel oil on fuel spray particulary parameters. SAE Tech. Pap. Ser. 2007, 2007-01-0488, 1-11. [CrossRef]

20. Kozak, W. Shaping Injection Parameters for Compression-Ignition Engines (Original: Ksztaltowanie Parametrow Wtyrysku Do Silnikow O Zapłonie Samoczynnym); Poznan Univeristy of Technology Publishing House: Poznań, Poland, 2008; pp. 43-67; ISBN 978-83-7143812-7.

21. Merkisz, J.; Kozak, M.; Kozak, W.; Bajerlein, M. Dissolving gas in diesel fuel as a way for fuel oxygenation and diesel exhaust emissions reduction. SAE Tech. Pap. Ser. 2007, 2007-01-2049, 1907-1914. [CrossRef]

22. Merkisz, J.; Bajerlein, M.; Kozak, W.; Markowski, J. The influence of CNG dissolved in the diesel fuel on the combustion process and concentration of toxic compounds in exhaust gas. SAE Tech. Pap. Ser. 2008, 2008-01-1815, 1-10. [CrossRef]

23. Battino, R.; Clever, H.L. The solubility of gases in liquids. Chem. Rev. 1966, 66, 395-463. [CrossRef]

24. Battino, R.; Rettich, T.R.; Wilhelm, E. Gas solubilities in liquid water near the temperature of the density maximum, Tmax $\left(\mathrm{H}_{2} \mathrm{O}\right)$ = 277.13 K. Mon. fuer Chem. Chem. Mon. 2018, 149, 219-230. [CrossRef]

25. Varberg, T.D.; Bendelsmith, A.J.; Kuwata, K.T. Measurement of the compressibility factor of gases: A physical chemistry laboratory experiment. J. Chem. Educ. 2011, 88, 1166-1169. [CrossRef]

26. Falkowski, H.; Hauser, G.; Janiszewski, T.; Jaskula, A. Diesel Fuel Injection Systems (Original: Uklady Wtryskowe Silnikow Wysokopreznych); Transport and Communication Publishers (Wydawnictwa Komunikacji i Lacznosci-WKiL): Warsaw, Poland, 1989; pp. 55-60; ISBN 83-206-0822-8.

27. Kozak, W.; Markowski, J. Coefficient of air and exhaust gas solubility in diesel fuel. Combust. Arch. 2003, 3, 50-61.

28. Xue, Y.; Du, Q.; Zhao, F.; Zhu, J. Dynamic analysis of a hypocycloid mechanism with planetary gears for internal combustion engine. In Proceedings of the 2008 Asia Simulation Conference-7th International Conference on System Simulation and Scientific Computing, Beijing, China, 10-12 October 2008; pp. 1012-1017.

29. Xu, X.; Xu, H.; Deng, H.; Gu, F.; Talbot, C. An investigation of a hypocycloid mechanism based twin-rotor piston engine. J. Mech. Eng. Sci. 2015, 229, 106-115. [CrossRef]

30. Aziz, E.S. Enhanced hypocycloid gear mechanism for internal combustion engine applications. J. Mech. Des. 2016, 138, 1-9. [CrossRef]

31. Munih, T.; Miljavec, D.; Corović, S. A novel design concept of electromagnetic valve actuator with high starting force. Energies 2019, 12, 3300. [CrossRef]

32. ElBahloul, M.A.; Aziz, E.S.; Chassapis, C. Mechanical efficiency prediction methodology of the hypocycloid gear mechanism for internal combustion engine application. Int. J. Interact. Des. Manuf. 2019, 13, 221-233. [CrossRef]

33. Jedlinski, L. A new design of gearboxes with reduced vibration and noise levels. Diagnostyka 2016, 17, 93-98.

34. Ruch, D.M.; Fronczak, F.J.; Beachley, N.H. Design of a modified hypocycloid engine. SAE Tech. Pap. Ser. 1991, 911810, 71-90. [CrossRef] 